\title{
НЕВЕРБАЛЬНАЯ СОСТАВЛЯЮЩАЯ НАУЧНО-ПОПУЛЯРНОГО ТЕКСТА
}

\section{NON-VERBAL COMPONENT OF POPULAR SCIENCE TEXT}

\section{N. Khristoforova}

Summary: The article explores the peculiarities of using the non-verbal component of a popular science text. The paper considers the correlation between non-verbal and verbal components in this type of text. The types of non-verbal means used in creating a video-verbal popular science text that serve to attract the reader's attention, inform him, and form his opinion are considered. Based on the analysis of examples containing nonverbal elements, the features of constructing a nonverbal component of the popular science text are revealed. This article discusses the following types of non-verbal tools used to create electronic popular science text: photos, drawings, video files, graphics, diagrams, color, and font. The object of our research is an electronic popular science text; the material for the study was the texts of the publications "Bild der Wissenschaft", "ScienceBlogs", "GEO", "Spiegel", "Focus".

Keywords: electronic popular science text, verbal components, non-verbal components, video-verbal text.
Христофорова Наталья Игоревна

к.филол.н., доцент, ФГБОУ ВО «Московский авиационный институт (национальный исследовательский университет)», г. Москва n_khristoforova@mail.ru

Аннотация: Статья исследует особенности невербальной составляющей научно-популярного текста, рассматривается корреляция между невербальной и вербальной составляющей в данном типе текстов. Рассмотрены виды невербальных средств, задействуемых при создании видеовербального научно-популярного текста, которые служат для привлечения внимания читателя, его информирования, формирования его мнения. На основании анализа примеров, содержащих невербальные элементы, выявлены особенности построения научно-популярного текста с невербальной составляющей. В данной статье рассматриваются следующие виды невербальных средств, использующихся при создании электронного научно-популярного текста: фотографии, рисунки, видеофайлы, графики, схемы, цвет, шрифт. 0бъектом нашего исследования выступает электронный научно-популярный текст, материалом для исследования послужили тексты изданий «Bild der Wissenschaft», «ScienceBlogs», «GE0», «Spiegel», «Focus».

Ключевые слова: электронный научно-популярный текст, вербальная составляющая, невербальная составляющая, видеовербальный текст.

взаимодействия вербальных и невербальных средств в смысловом пространстве современных видеовербальных текстов предлагают электронные научно-популярные тексты.

Исследуя невербальную составляющую научно-популярного текста нельзя не подчеркнуть наличие ее тесного взаимодействия с вербальной составляющей. Она не только дополняет смысл вербального сообщения, но и является источником информации о его авторе, поскольку единственная известная характеристика читателя - его многочисленность, поэтому при создании текста автор ориентируется на свои социальные, возрастные и другие особенности личности.

Как отмечают исследователи, исторически знак и его символика задействовался для пояснения мысли, дополняя вербальные средства [2]. Кроме того, знак может быть средством фиксации информации, поскольку «знаковая символика может использоваться для себя, быть частью внутреннего мышления индивида (мышление для себя), а может - для передачи мысли другим индивидам (мышление для других). В последнем случае мысль должна быть выражена индивидом максимально понятно для другого, ее выражение должно учитывать особенности мышления и знаний другого и предполагать 
эмпатию» $[2,81]$. Невербальные знаки не только отражают особенности мышления одного человека, но и могут их конструировать и моделировать наглядно, создавая таким образом новую реальность.

Невербальные компоненты могут не только сопровождать процесс создания научно-популярного текста, но и стереотипизировать и сократить его путём замены объемного и сложного описания предмета, рассматриваемого в тексте на знаки, понятные автору и читателю (фотографии, рисунки, рисунки-реконструкции, видеофайлы с изображением предметов, рассматриваемых в тексте, изображения исследователей, цвет изображений, выделение цветом, а также цветом и шрифтом). Следовательно, невербальные компоненты текста могут передавать большой объём информации, выступая как средство компрессии, а также создания представления о предмете текста, поскольку визуальная информация воспринимается и запоминается достаточно легко. Таким образом, взаимодействие автора и читателя стандартизируется, т.е. знак устанавливает стандарт восприятия, одинаковый для всех представителей конкретного сообщества в конкретной культуре. Например, красный цвет - указание на важность информации, черно-белая фотография в большинстве научно-популярных текстов указывает на момент прошлого и т.д. Однако было бы неверно сводить функцию невербальных средств в первую очередь к передаче информации. Невербальные средства привлекают внимание читателя, вызывают у него интерес к теме текста, упорядочивают информацию, помогая структурировать ее сознанием читателя вокруг себя благодаря свойству человеческой памяти воспринимать и усваивать, в первую очередь конкретную и наглядную информацию, способствуют лучшему пониманию и усвоению информации, а также побуждают сделать определенный вывод на основе этой информации (соответствующий цели автора текста). Можно утверждать, что понимание и осмысление сложной научно-технической информации читателями-неспециалистами происходит через сочетание невербальной и вербальной знаковых систем. Невербальные знаки делают научный мир и его исследователей «осязаемыми» для читателя-неспециалиста, создавая иллюзию коммуникации с исследователями, «приближая» исследователя к читателю, создавая мнимый «диалог». Такую функцию часто выполняют фотографии исследователей, фотографии исследователей за работой, видеофайлы, в которых исследователи рассказывают о предмете своих исследований, их результатах, своих открытиях. Рассмотрим наиболее репрезентативные примеры.

Интервью с антропологом [3] по поводу выходя его книги о происхождении и будущем патриархата начинается с его цветной фотографии на фоне густого зеленого леса. Судя по краткой справке о работе профессора, он много лет изучал орангутангов в естественных условиях жизни (Индонезии), этим можно объяснить выбор фона для интервью - его научные взгляды явно сложились под влиянием этой работы:

Besonders fasziniert den Anthropologen das äffische Erbe, das den Homo sapiens bis heute prägt. - Особый интерес для антрополога представляет собой «наследие обезьян», которое сих пор является характерными особенностями «человека разумного».

Руководитель института антропологии и музея Цюрихского университета, профессор смотрит на зрителясобеседника с большим вниманием и интересом, его руки скрещены на груди. Можно легко представить себя на месте журналистки, берущей интервью, и задающей вопросы, которые могут показаться достаточно наивными мудрому исследователю, ведь он может объяснить простым языком сложные вещи, а, следовательно, прекрасно разбирается в проблеме.

Фотография директора планетария города Гамбурга на черном фоне [4]:

Исследователь смотрит вверх, можно предположить, что в ночное небо, и размышляет, скорее всего о звездах - именно они интересуют его больше всего, он может рассказать много интересного, что подтверждается подписью-комментарием:

Professor Thomas W. Kraupe studierte Mathematik und Physik an der Universität München. Seit dem Jahr 2000 leitet er als Direktor das Planetarium Hamburg und hat es zum erfolgreichsten Sternentheater im deutschsprachigen Raum gemacht. An dieser Stelle wird er nun monatlich die Highlights am Sternenhimmel erklären, die uns erwarten. В планетарии (самом успешном в немецкоговорящих странах) под руководством профессора ежемесячно проходят интересные лекции.

Цветная фотография археологов за работой в Нижней Баварии [5]: археологи сфотографированы в момент раскопок и обсуждения уже найденных находок, все они очень заняты и не хотят отвлекаться. С другой стороны, предыдущие фотографии в тексте - фотографии их находок. Читателей приглашают рассмотреть их и почитать пояснения к ним, явно написанные со слов исследователей. Можно предположить, что археологи надеются на новые интересные находки и, может быть, даже открытия.

Журналист-автор раздела о расшифровке различных текстов и загадках нерасшифрованных текстов [6] внимательно смотрит на читателя, держа в руках (скорее всего, копию) одной из самых загадочных книг в мире, так называемой «Рукописи Войнича». Книга эта написана неизвестным автором на неизвестном языке, дата ее создания тоже неизвестна. Именно такие загадки и интересуют журналиста - одного из ведущих мировых экспертов по исторической расшифровке, о чем более 
подробно говорится в подписи к фотографии:

Klaus Schmeh zählt zu den weltweit führenden Experten für historische Verschlüsselungstechnik. Seine Bücher «Nicht zu knacken» (über die zehn größten ungelösten Verschlüsselungsrätsel) und «Codeknacker gegen Codemacher» (über die Geschichte der Verschlüsselungstechnik) sind Standardwerke. In «Klausis Krypto Kolumne» schreibt er über sein Lieblingsthema.

Кроме того, «традиционные графические знаки и символы, а также иные невербальные средства... отвечают за передачу эмоциональной составляющей..., с их помощью осуществляется воздействие» $[7,59]$ на читателя. Через невербальный компонент возможна передача вербального компонента, что влияет на создание впечатления и порождает оценочный компонент: по тому, насколько информативен научно-популярный текст с невербальной составляющей, насколько он привлекателен и красочен, читатель формирует свое первое впечатление обо всем издании, «делает или не делает выбор в... пользу - дает положительную или отрицательную оценку всему номеру издания» $[8,65-1]$.

В электронных научно-популярных текстах часто задействуются фотографии, рисунки, рисунки-реконструкции, схемы, а также видеофайлы, содержащие видеоизображение реальных местностей и объектов, схемы, графики, компьютерные модели, а также сопровождающий их текст. Например, текст [9] об исследовании поведения рыб с помощью специальных роботов, имитирующих движения рыб, начинается с цветной фотографии (с возможностью увеличения) плывущих рыб и роботов аналогичного размера и формы, подражающих их движениям с подписью, дающей читателю первое представление о результатах проведенных исследований:

Durch technische Nachbildungen von Fischen wird deutlich, wie sie durch das Schwimmen im Schwarm Energie sparen. (Bild: Dr. Liang Li, Max-Planck-Institut für Verhaltensbiologie) - Благодаря техническим имитациям исследователи выяснили, как рыбы экономят энергию, передвигаясь косяками. Изображение создано сотрудником Института медицинских исследований Общества Макса Планка, что свидетельствует о высоком уровне проведенных исследований.

Завершается текст цветным видеофайлом, состоящим из: видеосъемок плавающих косяков рыбы с наложенным текстом (основными положениями исследований), а также «видеоотчета» об этапах исследований, включающего:

1. компьютерные модели движения рыб с наложенным текстом- комментариями к исследованиям;

2. съемки движения роботов размера и формы, аналогичных размеру и форме рыб, имитирующих движения рыб с наложенным текстом-комментариями;

3. небольшие видеоизображения движения робо- тов-имитаторов и цветного графика, являющегося графическим выводом из исследования и краткого текста-комментария;

4. съемки движения рыб с отмеченными цветом «сигнальными» точками, на основании данных которых был выстроен график (с помощью компьютерной графики он «возникает» по мере движения рыб) и краткий текст-комментарий.

Далее вновь используются видеосъёмки плавающих косяков рыбы с наложенным текстом (первой частью вывода из исследований: «был пролит свет на преимущества движения косяком»), а также видеосъёмки плавающих роботов-рыб с наложенным текстом (второй частью вывода: «это может вдохновить на создание нового вида роботов»), а потом плавающих рыб и роботов вместе с наложенным текстом (третьей частью вывода: «благодаря этом возможна интеграция природы и роботизированных систем»).

Отметим также, что весь письменный текст видеофайла - на английском языке, а звуковой комментарий на немецком языке, что способствует и интересу к информации, и её пониманию.

Немаловажную роль в научно-популярном тексте играет и шрифт, причём шрифтовое варьирование можно рассматривать как психологическое воздействие, оказываемое на читателя.

Для выделения конкретного слова или выражения используются жирный шрифт или курсив, обладающие «информатической, выделительными функциями, функцией маркирования чужой речи и даже функцией «эмоционального ключа» [8, 65-2]: указывающие на эмоциональную нагрузку выделенного фрагмента, что способствует передаче эмоционально-оценочного компонента. Так, текст об опасности последствий высыхания болот [10] начинается с цветной фотографии болота в Нижней Саксонии с подписью: Huvenhoopsmoor in Niedersachsen. Шрифт подписи меньше и светлее основного текста статьи. Основной текст же начинается с выделения жирным шрифтом:

Es liegt da wie eine verwunschene Märchenlandschaft. Tümpel wechseln sich ab mit Inseln aus Gagelstrauch und Torfmoos. Sumpfkalla und Königsfarn stehen im Nass. Ein Moorfrosch hüpft durchs Gras.

Можно говорить о смысловом выделении, основанном на контрасте: пока все это, такое привычное и красивое, еще существует (Es liegt da - здесь), мы и представить себе не можем, что может быть иначе, но экосистема в опасности: каждое высохшее болото способствует глобальному потеплению.

На фоне однородного текста информация, которая 
выделена жирным шрифтом и/или курсивом, привлекает большее внимание, что указывает на важность этого фрагмента, что способствует его более детальному изучению читателем и формированию у него положительной или отрицательной оценки представленной информации. В приведенных ниже примерах именно разнообразие применяемых шрифтов является основным способом визуализации, без него адекватное прочтение текста было бы невозможным. Гармонично сочетая языковые и неязыковые знаки в смысловом пространстве научно-популярного текста, автор одновременно развивает нескольких персонажей и несколько сюжетных линий, реализуя характерную для научно-популярного текста нелинейность повествования.

Так, с помощью жирного шрифта выделаются основные моменты текста [11]: подзаголовок, объясняющий, почему так важно «поставить точку» в вопросе, какими были германцы, которых и кино, и музеи, и книги традиционно изображают «бородачами, пьющими пиво»:

Egal, ob bei Netflix, im Museum oder auf dem Buchmarkt: Die Germanen erfreuen sich derzeit wachsender Beliebtheit. Aber bis heute dominieren viele Vorurteile das Bild, das wir von unseren noch immer geheimnisumwitterten Ahnen haben. Zeit, damit Schluss zu machen.

Далее жирным шрифтом выделяется каждый раздел основного текста:

Bärtige Männer, die ständig Bier trinken

Ausstellung rückt das Bild zurecht

Приводится в тексте и список предубеждений, опровергнутых историком, причем название этого раздела текста, а также аргументы историка выделены жирным шрифтом, например:

Zehn Vorurteile widerlegt

Doch was sind die Vorurteile, die es bis heute über die Germanen gibt? Und wie sah die Realität aus? Der Alt-Historiker Heiko Steuer hat zehn dieser Vorurteile zusammengefasst und sie widerlegt.

Sie seien unter anderem fasziniert gewesen von den ausgedehnten dunklen Wäldern Germaniens, erklärten die Macher der sechssteiligen „Barbaren“-Serie. Anders als dort dargestellt, bestand das von den Germanen besiedelte Gebiet keineswegs zum großen Teil aus dunklen Wäldern.
Tatsächlich lag der Anteil des Waldes am germanischen Siedlungsgebiet bei rund 30 Prozent - und damit ziemlich genauso hoch wie heute in Deutschland.

На основании выделения жирным шрифтом можно построить следующий план условного «второго» текста, представляющего, в отличие от «первого» текста, вторую точку зрения (точку зрения историка, специалиста по данной теме):

Важно разрешить противоречия и рассказать, кто такие германцы.

Мнения историков прошлого

Выставка на «Музейном острове», действующая сейчас, избавляет нас от клише прошлого

Опровержение историком 10 распространенных предубеждений.

Таким образом, автор использует разные полиграфические шрифты не только ради отделения одной синтаксической конструкции от другой, он структурирует текст, создает эффект полифонии текста - своеобразные диалог двух точек зрения на проблему, максимально упрощая при этом прочтение и понимание текста. «Интересно отметить тот факт, что невербальная информация способна изменять вербальное сообщение» $[12,30]$.

Подводя итоги, заметим, что невербальные компоненты научно-популярного текста в сочетании с вербальными, придают им большую выразительность, эмоциональность, привлекают внимание читателя и повышают у него интерес к рассматриваемой теме, способствуют лучшему усвоению информации. Для достижения коммуникативного успеха научно-популярного текста авторы используют самые разнообразные невербальные средства. Роль невербальных компонентов в научно-популярном тексте заключается в повышение уровня понимания содержания текста. Невербальные компоненты передают информацию, регулируют процесс чтения текста, дополняют, подтверждают или опровергают вербальную информацию, позволяют контролировать процесс усвоения новой информации, делая его более успешным, а также способствуют формированию оценки предоставленной информации. Учитывая культурно-специфические черты читателя и автора научно-популярного текста, процесс чтения текста можно сделать наиболее эффективным.

\section{ЛИТЕРАТУРА}

1. Гусева А.П. Полифония и ее вербальные и невербальные проявления в поликодовом художественном тексте//Вестник МГЛу. Гуманитарные науки, Москва, 2019. № 7 (823), с. 88-98. Стр. 89

2. Печурина 0.А. Гипотеза о происхождении некоторых невербальных знаков и их символики//Вестник Северного (Арктического) университета. Серия: Гуманитарные и социальные науки, Архангельск, 2020. № 3, с. 79-90. Стр. 81 
3. Bredow, Rafaela von. Gregor-Teleskop Das Patriarchat ist eine Anomalie in der Menschheitsgeschichte// Spiegel. 2020. [электронный ресурс] - Режим доступа. - URL: https://www.spiegel.de/wissenschaft/mensch/das-patriarchat-ist-eine-anomalie-in-der-menschheitsgeschichte -а-00000000-0002-0001-0000-000174103658 (дата обращения: 20.11.2020 г.)

4. Jetzt wird der Mars zum König der Planeten// GE0. 2020. [электронный ресурс] - Режим доступа. - URL: https://www.geo.de/wissen/weltall/23277-rtklhighlights-am-sternenhimmel-jetzt-wird-der-mars-zum-koenig-der-planeten (дата обращения: 23.11.2020 г.)

5. frw/dpa Donauausbau in Niederbayern: Experten entdecken Hunderte archäologische Funde// Focus 2020. [электронный ресурс] - Режим доступа. - URL: https://www.focus.de/wissen/mensch/archaeologie/erhaltungszustand-aussergewoehnlich-gut-donauausbau-in-niederbayern-hunderte-archaeologischefunde-entdeckt_id_12290661.html (дата обращения: 06.08.2020 г.)

6. Über den Autor//ScienceBlogs. 2020. [электронный ресурс] - Режим доступа. - URL: https://scienceblogs.de/klausis-krypto-kolumne/meine-artikel/ (дата обращения: 25.11 .2020 г.)

7. Смагина Е.С. Невербальные способы воздейственности в интернет-коммуникации//Метеор-Сити, Челябинск, 2017. № 2 (8), с. 58-62. Стр. 59

8. Волкова Е.А. Оценочный компонент невербальных средств коммуникации во французской прессе// Аcademу. НИУ БелГУ, Иваново, 2018. № 1 (28), c. 64-65. Стр. 65-1, 65-2.

9. Vieweg, Martin. Schwarm-Forschung mit Fisch-Robotern. 2020. [Электронный ресурс] — Режим доступа. — URL https://www.wissenschaft.de/technikdigitales/schwarm-forschung-mit-fisch-robotern/ (дата обращения: 26.10 .2020 г.)

10. Bethge, Philip. Trockene Moore sind Klimakiller// Spiegel. 2020. [электронный ресурс] - Режим доступа. - URL: https://www.spiegel.de/wissenschaft/natur/ klimaschutz-wie-sich-moore-retten-lassen-a-00000000-0002-0001-0000-000173622000 (дата обращения: 19.11.2020 г.)

11. Fuhrer, Armin. Bärtige, biertrinkende Männer? Historiker sagt, wie unsere Vorfahren wirklich waren// Focus. 2020. [электронный ресурс] - Режим доступа. - URL: https://www.focus.de/wissen/mensch/geschichte/neue-netflix-serie-barbaren-gestartet-die-germanen-ein-ganz-und-gar-unzivilisiertes-volk_ id_12590955.html (дата обращения: 01.11.2020 г.)

12. Журавлёва Е.В. Особенности невербального поведения телеведущего//Наука, образование и культура, 2017. Том 2, № 5 (20), с. 30-33. Стр. 30.

(c) Христофорова Наталья Игоревна (n_khristoforova@mail.ru).

Журнал «Современная наука: актуальные проблемы теории и практики»

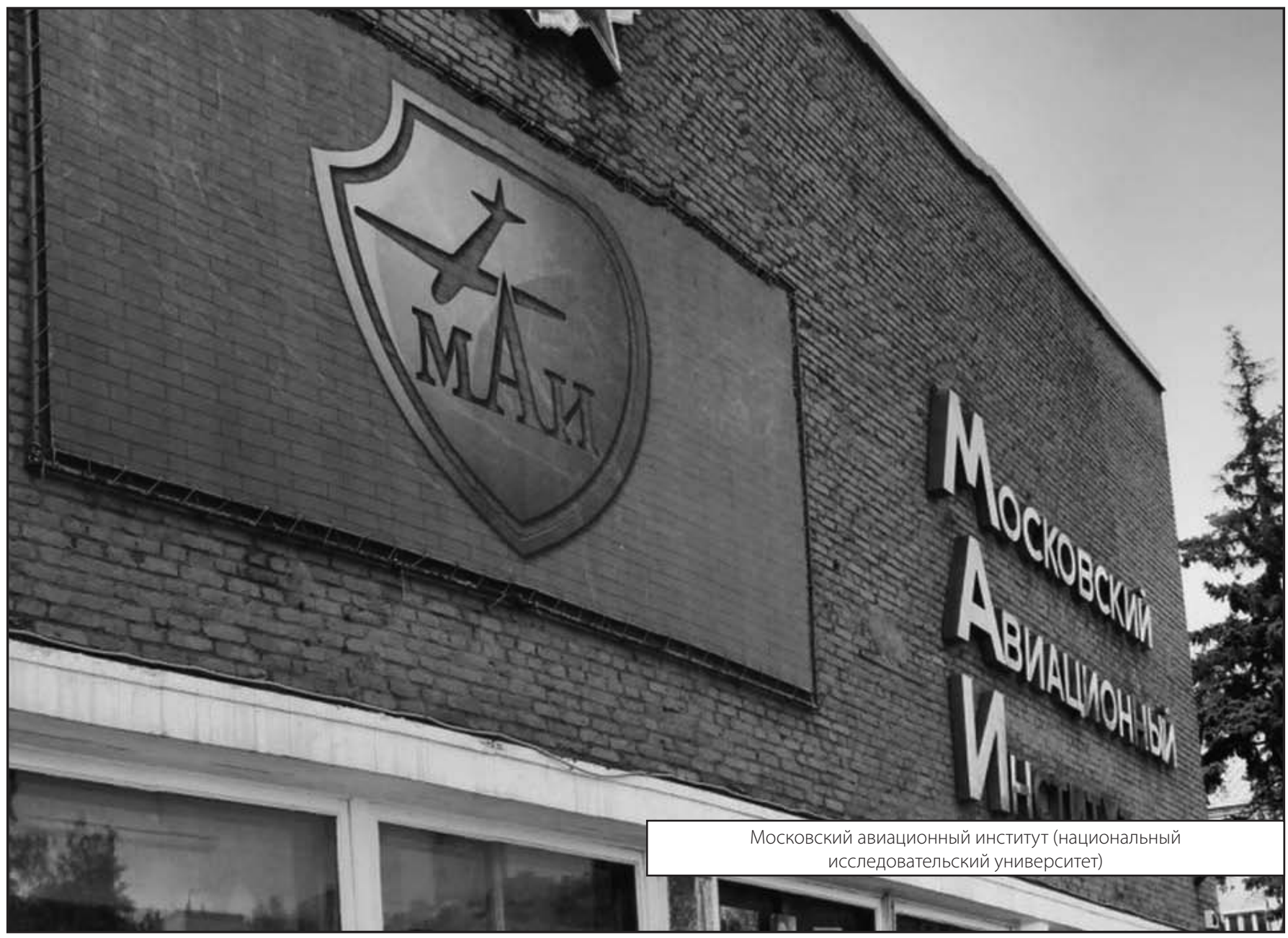

